espacio metropolitano presentan grados importantes de continuidad", pág.58; "persistencia de una fuerte concentración de hogares de ingreso medio alto y alto en la ciudad central, al mismo tiempo que una presencia también significativa de los mismos, pero menos marcada, en algunas jurisdicciones de carácter peri-central”, pág.81;), cuando no contiene observaciones cuestionables que parecen ignorar la configuración histórica de la ciudad ("una avenida como Insurgentes, que atraviesa de norte a sur la capital, ha ido progresivamente haciendo retroceder sus fachadas para ganar espacio de estacionamiento destinado a los automóviles de sus clientes", pág.150; “el significado socio-cultural de una compra es inseparable del lugar donde la misma se realiza”, pág. 283).

En conjunto el trabajo retoma aspectos centrales de los problemas planteados por las grandes metrópolis, con pluralidad de ejemplos y rigor en el análisis de casos puntuales. En su recorrido por la evolución urbana reciente pone a disposición del lector un amplio muestrario de los rasgos contemporáneos de las grandes ciudades y sus problemas.

Reseña

Matías Kulfas

\title{
Los tres kirchnerismos. Una historia de la economía argentina 2003-2015.
}

Primera edición - Buenos Aires: Siglo Veintinuno Editores, 2016. 240 pags. ISBN 978-987-629-633-5 Universidad Nacional de Lanüs
¿Puede la academia abordar la política económica del kirchnerismo para ofrecer una síntesis consistente del período e invitar a defensores y detractores a dialogar con argumentos? Esta pregunta refleja el objetivo del libro de Matías Kulfas. En él el autor se propone realizar un balance del período de la posconvertibilidad, incluyendo una contextualización histórica, asumiendo el desafio de reflexionar acerca de los avances y limitaciones que tuvo el modelo económico "K”.

Matías Kulfas, Licenciado en Economía por la Universidad de Buenos Aires, con estudios de posgrado en Flacso sede Argentina, se ha desempeñado como investigador y consultor pero también ha desarrollado parte de su carrera en la función pública, en el Ministerio de Economía de la Nación, en el Banco Nación y en el Banco Central. En el marco de los estudios económicos heterodoxos, Kulfas ha investigado las problemáticas vinculadas al desarrollo económico, el comportamiento del empresariado nacional y transnacional, como el 
impacto de la inversión extranjera directa, la fuga de capitales, el desempeño del sector productivo, particularmente de las pequeñas y medianas empresas en Argentina.

El libro pone en debate la gestión de la política económica del kirchnerismo. El autor da cuenta de la polarización creciente entre los defensores y los detractores del modelo económico, por lo tanto, esta obra pretende sobrevolar los desacuerdos, planteando un enfoque históricamente situado y estadísticamente fundado.

Para lograr su objetivo, Kulfas utiliza una estrategia metodológica cuantitativa basada en datos estadísticos del Ministerio de Economía de la Nación, del Banco Central, el Ministerio de Trabajo, y organismos internacionales como la CEPAL y el Fondo Monetario Internacional. También sumó una revisión bibliográfica sobre el período en cuestión, su experiencia en la gestión y entrevistas a informantes clave del gobierno para incorporar al trabajo una perspectiva cualitativa. El análisis estadístico que sustenta la elaboración del libro resulta un aporte significativo, más aún en un contexto en el cual las estadísticas no fueron fiables para realizar investigaciones consistentes en materia económica desde la intervención del INDEC en el año 2007.

El trabajo está estructurado en seis capítulos. En los dos primeros elautor sintetiza los ejes conceptuales en debate (Capítulo 1) y desarrolla el contexto histórico en el cual considera que hay que enmarcar el análisis del período 2003-2015 (Capítulo 2). Los capítulos 3,4 y 5, comprenden un análisis las tres subetapas, conformadas por el gobierno de Néstor Kirchner (2003-2007) y los dos de Cristina Fernández de Kirchner (20072011 y 2011-2015). Mediante esta distinción temporal se propone evidenciar que los gobiernos no fueron homogéneos sino que presentaron distintas tendencias, logros y estilos de gestión. Por último, el Capítulo 6 resume los límites de la estrategia productiva.

En el primer capítulo, se introducen los debates sobre el desempeño de la macroeconomía del período. Uno de ellos es si la década fue el ciclo de crecimiento acelerado más importante en la historia del país. El autor plantea que durante otras períodos históricos la economía también creció fuertemente (1903-1913, 1918-1929, 1933-1944, 19641974), por lo que no fue el único momento, pero sí fue muy importante por su magnitud: un incremento promedio por año del $6.7 \%$ del PBI. Otra discusión es acerca de los factores dinamizadores de dicho crecimiento -políticas internas o contexto externoKulfas explica que si bien es evidente la influencia de los altos precios internacionales de las materias primas, el crecimiento no se produjo solamente por el "viento de cola" sino que también la gestión de la política económica del gobierno fue importante teniendo en cuenta lo que sucedió en los otros países de la región. Cuando algunos países vecinos tuvieron mejores precios de sus commodities (minería e hidrocarburos en Chile, Perú, Bolivia y Venezuela), reprimarizaron su economía y no tuvieron el mismo desempeño en variables claves como el nivel de desempleo y de crecimiento industrial. Por lo tanto, a pesar de que el contexto internacional marcó cierta tendencia, evidenciada también por el impacto de la crisis de las hipotecas subprime en 2008, el país tuvo mayores grados de autonomía para definir la política económica.

En el Capítulo 2 se sitúa históricamente la posición económica de la Argentina, comparando su desempeño respecto a otros países desde fines del siglo XIX hasta la actualidad. Como síntesis, se desestima la afirmación de que la salida del modelo agroexportador implicó la declinación económica del país. Este capítulo también analiza lo ocurrido durante el período de industrialización por sustitución de importaciones (ISI) para cotejar las hipótesis sobre su agotamiento. El pensamiento económico ortodoxo consideró que la causa del agotamiento de la ISI fue su propia insostenibilidad económica. Kulfas refuta esa hipótesis y sostiene que el quiebre definitivo de la industrialización fue el proyecto político-económico de la dictadura militar de 1976. En la década de 1960, el país había comenzado a exportar productos industriales, modificando su inserción en el comercio internacional por lo que el agotamiento no era tal.

En los capítulos 3, 4 y 5 se realiza un recorrido por la política económica de los tres gobiernos kirchneristas. En mayo de 2003 asumió Néstor Kirchner, quien inició un proceso que el autor llama estabilización heterodoxa. Matías Kulfas destaca algunas medidas como la política cambiaria, la consolidación de los superávits gemelos -fiscal y comercial-; la reestructuración de la deuda externa; las políticas sociales redistributivas mediante la transferencia de ingresos para los sectores populares, la generación de nuevos puestos de trabajo y la consolidación de los Convenios Colectivos de Trabajo para la negociación de los aumentos salariales, que privilegiaron el consumo y la expansión del mercado interno. Kirchner finalizó el gobierno en un contexto de recuperación del crecimiento económico.

El segundo período, el primer gobierno de CFK, debió afrontar dificultades tanto políticas como económicas desde la primera hora por el revés político que implicó la nosanción de la ley que avalara la Resolución 125. Por otro lado, la coyuntura internacional generó fuertes consecuencias para la economía nacional. Si bien desde 2006 el país contaba con términos del intercambio favorables por los altos precios internacionales de la soja, logrando un balance comercial positivo, el estallido de la crisis internacional tuvo un importante impacto en la economía real. La crisis repercutió negativamente, no por la vía financiera, sino en el nivel de exportaciones argentinas que disminuyeron afectando la balanza comercial.

A este escenario se sumó la reaparición de la inflación en 2007, que llegó a ser del $25 \%$, provocando como consecuencia un importante malestar social. Como respuesta, el gobierno reaccionó con la sanción de algunas medidas contracíclicas destinadas a la reactivación del mercado interno y al sostenimiento de la demanda agregada: 
la Asignación Universal por Hijo, viable económicamente por la recuperación de los aportes patronales; la incorporación de personal estatal; el aumento de los salarios mediante acuerdos paritarios por encima del valor de la inflación; el incentivo a la obra pública y las medidas destinadas al sostenimiento de los niveles de empleo industrial. La efectiva reacción del gobierno en el sostenimiento del modelo económico a pesar de los primeros indicios de limitaciones y obstáculos, sumada a la muerte del ex presidente Néstor Kirchner, revalorizó sus logros, dando continuidad al Frente para la Victoria en las elecciones de 2011

En su discurso de reasunción del cargo, la presidenta dio cuenta de la necesidad de realizar un salto en el modelo macroeconómico, caracterizado como "sintonía fina". Sin embargo, en lugar de una profundización del modelo, se debió apelar a su sostenimiento. Entre las dificultades emergentes se encontraron el déficit fiscal y la alta inflación. El déficit fiscal se produjo por las limitaciones productivas de la industria (automotriz y ensamblaje de productos electrónicos en Tierra del Fuego) y por el déficit energético, resultado del significativo costo del mantenimiento del subsidio a los servicios públicos que impactó tanto en la balanza comercial, como en el nivel del gasto público por el sostenimiento de los subsidios a las empresas privatizadas durante los años noventas.

La inflación y la presión sobre el tipo de cambio llevaron a decidir la restricción a la compra de divisa extranjera, generando el rechazo de los sectores medios acostumbrados a ahorrar en dólares. El sorpresivo conflicto con los fondos buitres sumó otra dificultad por la cual el gobierno terminó enfrentando desajustes macroeconómicos que produjeron cierto estancamiento económico.

El capítulo final realiza un balance de la economía kirchnerista. Como resultado, se observa que no se produjeron cambios estructurales, es decir que no se transformó la matriz productiva del país: no se crearon nuevos sectores económicos ni dejaron de tener preponderancia rubros como la producción de alimentos y bebidas. Sí se produjo una modificación en el patrón de acumulación, de valorización financiera a productiva: se recuperó la industria con la cual creció el empleo y la participación de los trabajadores en la distribución del ingreso, se crearon pymes y se distribuyó el ingreso mediante políticas sociales activas. Las falencias en la implementación de una política industria integral y la ausencia de la coordinación estratégica entre las diferentes áreas del Estado (Industria, Ciencia y Tecnología, Educación, Banco Central, entre otros) generaron el resurgimiento de la restricción externa, una problemática estructural de la Argentina.

Para concluir, Kulfas reflexiona acerca de los legados del kirchnerismo en materia económica, entre los cuales destaca la recuperación del rol del Estado como interventor en la economía y en la conducción política del rumbo económico, contraria a la tecnocratización de los elencos económicos durante el neoliberalismo. Sin embargo, el autor ob- serva que a pesar de la ductilidad y la vocación de gestión para solucionar las dificultades políticas coyunturales -tales como el conflicto del "campo", el "cepo cambiario", el litigio contra los fondos "buitre" -el kirchnerismo no tuvo una visión de planificación en el largo plazo y en ese marco, no logró consolidar un modelo de desarrollo alternativo para sustituir al neoliberalismo reinante a nivel mundial. Esta carencia es analizada como una dificultad regional: ninguno de los gobiernos latinoamericanos que pusieron en cuestión el régimen neoliberal, pudo constituir un sistema alternativo de acumulación.

Este libro es el paso inicial para pensar de forma integrada el ciclo económico kirchnerista. De lectura accesible a un público amplio, el autor logra condensar la trayectoria de la economía durante el período e incorpora como variable a su análisis las controversias políticas que debió atender el gobierno desde una perspectiva electoral. Entre las virtudes del libro se encuentra su consistencia argumentativa lograda a partir de los cuadros estadísticos y los gráficos anexados al final de cada capítulo. Otro aporte significativo es que Kulfas invita a reflexionar sobre la definición del estilo de desarrollo nacional. Si bien el kirchnerismo tuvo vocación industrializadora y priorizó un proyecto redistributivo, de inclusión social, terminó enfrentando problemas de consistencia macroeconómica, poniendo en jaque las mismas políticas impulsadas por el gobierno.

Sin embargo el texto deja sin trabajar el rol de los distintos sectores empresariales. El libro se inscribe dentro de la corriente estructuralista, pero no presenta una perspectiva de economía política; no incluye las acciones de empresarios nacionales y foráneos como variable que condiciona las relaciones de poder e incide en la toma de decisiones en materia económica.

Otra pregunta que podría realizarse es si el intento de síntesis no es muy reciente a la finalización del gobierno, suponiendo que la distancia temporal le podría otorgar luego valor agregado al análisis. Sin embargo, frente a la finalización del ciclo iniciado en 2003 gran cantidad de trabajos académicos se encuentran sistematizando las particularidades económicas del periodo. Este trabajo constituye un verdadero aporte en este sentido, demostrando que se puede realizar un análisis consistente de la política económica de los tres gobiernos kirchneristas, tratando de salvar las distancias entre quienes valoran positivamente la denominada "década ganada" y quienes la consideran perdida. 